Neurologist. 2008 May ; 14(3): 181-191. doi:10.1097/NRL.0b013e31816606b9.

\title{
Malformations of cortical development
}

\author{
Trudy Pang, MD, \\ Department of Neurology, Beth Israel Deaconess Medical Center, Harvard Medical School, \\ Boston, Massachusetts
}

Ramin Atefy, MD, and

Department of Neurology, Beth Israel Deaconess Medical Center, Harvard Medical School, Boston, Massachusetts

Volney Sheen, MD PhD

Department of Neurology, Beth Israel Deaconess Medical Center, Harvard Medical School, Boston, Massachusetts

\section{Abstract}

Background-Malformations of cortical development (MCD) are increasingly recognized as an important cause of epilepsy and developmental delay. MCD encompass a wide spectrum of disorders with various underlying genetic etiologies and clinical manifestations. High resolution imaging has dramatically improved our recognition of MCD.

Review Summary-This review will provide a brief overview of the stages of normal cortical development, including neuronal proliferation, neuroblast migration, and neuronal organization. Disruptions at various stages lead to characteristic MCD. Disorders of neurogenesis give rise to microcephaly (small brain) or macrocephaly (large brain). Disorders of early neuroblast migration give rise to periventricular heterotopia (neurons located along the ventricles), whereas abnormalities later in migration lead to lissencephaly (smooth brain) or subcortical band heterotopia (smooth brain with a band of heterotopic neurons under the cortex). Abnormal neuronal migration arrest give rise to over-migration of neurons in cobblestone lissencephaly. Lastly, disorders of neuronal organization cause polymicrogyria (abnormally small gyri and sulci). This review will also discuss the known genetic mutations and potential mechanisms that contribute to these syndromes.

Conclusion-Identification of various gene mutations has not only given us greater insight into some of the pathophysiologic basis of MCD, but also an understanding of the processes involved in normal cortical development.

\section{Keywords}

Cortical development; malformations; genes

\section{Introduction}

Malformations of cortical development (MCD) are an important cause of epilepsy and developmental delay. It is estimated that up to $40 \%$ of children with refractory epilepsy have a cortical malformation ${ }^{1}$. MCD encompasses a large spectrum of disorders related to abnormal cortical development with varied genetic etiologies, anatomic abnormalities, and

Correspondence and Reprints: Volney Sheen MD PhD, Department of Neurology, Beth Israel Deaconess Medical Center, Harvard Medical School, Boston, Massachusetts 02215, USA, Tel: 617-667-2699, Fax: 617-667-0800, vsheen@ bidmc.harvard.edu. 
clinical manifestations. Whereas many of these disorders were previously diagnosed at autopsy, the use of MRI has dramatically improved our ability to recognize these MCD.

Cerebral cortical development involves a set of highly complex and organized events, including neural stem cell proliferation, migration, and finally neuronal differentiation. Disruptions of these various stages may result in MCD. Disorders due to abnormalities of cell proliferation may cause microcephaly (meaning small brain), megalencephaly (meaning large brain), or cortical dysplasia (meaning focal areas of abnormal neuronal architecture). Disorders of initiation of neuronal migration result in periventricular heterotopia (meaning abnormal nodules of neurons located along the ventricular wall). Disorders of later migration and motility cause disruption of the normal six-layered cortex, such as classical lissencephaly (meaning smooth brain) and subcortical band heterotopia (meaning heterotopic neurons located midway between the surface of the brain and lateral ventricles). Finally, disorders of neuronal arrest can result in neurons that fail to stop upon reaching their intended destination in the cerebral cortex and over-migrate onto the cortical surface as seen in cobblestone lissencephaly. Although cortical development has been separated into these stages, there is significant overlap between the stages and many abnormalities may cause dysfunction at more than one level. Thus, malformation syndromes are typically classified based on the earliest disruption of development. These concepts serve as the basis for the latest classification scheme for these disorders ${ }^{2}$.

The pathogenesis of these malformations is multifactorial: genetic mutations or environmental insults, whether acquired in utero at different stages of brain development, or during the perinatal or postnatal period after corticogenesis may all contribute to the development of these syndromes ${ }^{3,4}$. The timing, severity, and type of environmental influences, as well as genetic factors, will ultimately determine the type and extent of malformation syndrome.

Work in elucidating the genetic basis of various MCD has given us greater insight and understanding into the underlying pathophysiologic basis of these disorders, and will form the focus of this review. Different mutations of the same gene can cause different phenotypes, based on the degree of protein dysfunction (so termed genotype-phenotype correlation). Loss or disruption of the functional domains within a gene ultimately determines the phenotype of the disorder. Alternatively, specific mutations in a given gene can also lead to a gain of function for the aberrant protein. Mosaicism can occur when the mutation is present in a subpopulation of cells, whereas germ line mutations typically lead to expression of the mutant gene in all cells. Functional mosaicism occurs due to Xinactivation in which the mutation is present on one $\mathrm{X}$ chromosome but not the other. The mutant gene is thus expressed only in cells in which the mutant gene is found on the active $\mathrm{X}$ chromosome. This process explains why affected females are often less severely affected than males who have the same mutation. An understanding of some of the underlying genetic basis for these disorders will play an important role in genetic counseling of affected individuals and their families.

\section{Normal cortical development}

Human cortical development encompasses a series of complex and overlapping processes, including neuronal precursor proliferation at the ventricular zone, neuroblast departure from the ventricular zone, neuroblast migration, migration arrest, and neuronal organization.

Neuronal progenitor cells originate from the periventricular and subventricular zones and undergo different patterns of development and migration paths, before they eventually populate the cerebral cortex. Neural precursor cells may undergo cell division in symmetric and asymmetric patterns. Symmetric cell division yields two identical daughter cells that 
continue to divide in a similar fashion and serve to replenish the population of progenitor cells. Asymmetric cell division leads to two different types of cells: 1. progenitor cells that re-enter the cell cycle, 2. immature neuronal cells (neuroblasts) that will migrate into the overlying cortical plate 5 .

Migration of neuroblasts begins with appropriate orientation of the cells prior to departure from the ventricular zone and these neuroblasts must have the ability to adhere to the scaffolding created by the radial glia that guide them during migration. To ensure correct orientation, the neuroblasts actually move in a retrograde fashion and make contact with the ventricular surface before migrating out to the cortical plate ${ }^{6}$. Excitatory or glutamatergic cortical neurons have a leading process that adheres to the radial glial fibers as they migrate radially from the ventricular zone to the cerebral cortex. Inhibitory or GABAergic cortical interneurons originate from the germinal zone of the basal ganglia and the ventricular zone. Rather than migrating radially, immature neurons from the lateral, medial, and caudal ganglionic eminences migrate tangentially first, and then radially to the various layers of the cerebral cortex $6,7,8,9$.

Migrating neurons must stop in their appropriate laminar position once they reach the cortical plate. The cerebral cortex develops in an "inside-out" fashion. In other words, the earlier generated neurons form the deeper layers (V/VI) while later-generated neurons migrate past the earlier formed neurons to form the superficial layers (II/III). Both structural barriers at the pial surface of the brain and molecular stop signals are involved in mediating neuronal migration arrest ${ }^{10}$. Finally, cortical connections formed during gestation and infancy are modified through pruning of synapses and cellular apoptosis.

\section{Disorders due to abnormal neurogenesis}

The balance between cell proliferation and cell death determines the ultimate number of neurons or glia in the developed brain. Diffuse perturbations in this delicate balance (or perturbations occurring very early in development such that subsequent cell progeny are affected) results in microcephaly or macrocephaly. Focal disruptions (typically due to mosaicism) can lead to focal cortical dysplasia.

\section{Microcephaly}

Microcephaly, or small brain, refers to a head circumference that is more than two standard deviations below the population mean after correction for age and sex. It may result from abnormal cell division or proliferation. A number of processes can cause microcephaly and are often accompanied by involvement of other organ systems. Primary microcephaly, known as microcephaly vera, refers to a small brain which results from processes affecting cortical development alone without involvement of other organs. On pathologic examination, occasionally, a simplified gyral pattern (oligogyria) and disruption of the gray matter along the ventricular zone may be seen, along with hypomyelination and cerebellar hypoplasia. Clinically, these patients have mental retardation and some may also have epilepsy. Radiographic findings are determined by the underlying cause of microcephaly. In primary microcephaly, a grossly normal brain (Figures 1A and 1B) is frequently seen on brain MRI ${ }^{11}$.

Four autosomal recessive genes are associated with microcephaly (Table 1), namely, Microcephalin, ASPM (abnormal spindle-like, microcephaly-associated), CDK5RAP2 (CDK5 regulatory subunit associated protein 2) and CENPJ (centromere protein J). These genes seem to play a role in cell division during neurogenesis at the ventricular neuroepithelium. The Microcephalin gene is thought to also play a role in DNA repair. Abnormal DNA repair due to loss of the Microcephalin gene causes increased neural 
progenitor cell death along the ventricles. Additional studies suggest that the Microcephalin protein is a centrosomal protein ${ }^{12}$ and plays a role in the control of cell-cycle timing ${ }^{13}$. $A S P M$ is a gene that encodes for a very large centrosomal protein ${ }^{14}$ that is essential for normal neuroblast mitotic spindle function in Drosophila ${ }^{15}$. CDK5RAP2 and CENPJ encode for centrosomal proteins that are found at the spindle poles of mitotic cells, along the ventricular neuroepithelium. Thus, all of the known genes for microcephaly vera play an important role in neurogenesis by regulation of microtubules and cell cycle progression during cell division ${ }^{16,17}$.

Disruption of genes involved in microtubule and centrosome function in mice results in similar impairments in neural progenitor proliferation and cause microcephaly 18 . For example, Nde1 is a microtubule-associated protein required for centrosome duplication, and the formation and function of the mitotic spindle. Nde1 expression is also associated with the centrosome, kinetochore, and spindle. Phosphorylation of the protein during mitosis causes it to associate with mitotic spindles and participate in dynein-mediated transport of kinetochore proteins to spindle poles along microtubules during proliferation. Loss of mouse Nde1 function in cortical progenitors causes defects in mitotic progression, mitotic orientation, and mitotic chromosome localization in cortical progenitors. This disruption in centrosome duplication and mitotic spindle assembly produces a small brain in Nde1 deficient mice.

\section{Hemimegalencephaly}

Hemimegalencephaly is characterized by overgrowth of one hemisphere, a part of a hemisphere, or one hemisphere with partial involvement of the other hemisphere. The pathology typically reveals cortical dysplasia, white matter abnormalities, abnormal cell types, and polymicrogyria. Hemimegalencephaly may be an isolated finding or it may exist as a feature of a number of syndromes, including neurocutaneous syndromes such as Klippel-Trenauney syndrome and hypomelanosis of Ito ${ }^{19}$. Not surprisingly, given the significant brain malformation, patients typically have mental retardation and almost always have epilepsy which can become intractable. Seizures may begin within the first 6 months of life, often with partial onset arising from the enlarged area of the brain with or without secondary generalization. Infantile spasms and atonic seizures can also occur. Typical MRI findings include enlargement of at least one lobe or one hemisphere, with the occipital region being the most frequently involved ${ }^{11}$. The underlying white matter may also demonstrate abnormal T1 and T2 signal intensities. The cortex is often thick with pachygyria and heterotopia are commonly seen scattered in various locations. The lateral ventricle is usually enlarged with a straight and pointed frontal horn. The underlying genetic abnormalities are still unclear and additional work is needed to elucidate the heterogeneous genetic bases of this disorder.

\section{Focal cortical dysplasia}

Focal cortical dysplasia (FCD) represents a heterogeneous entity resulting from a variety of causes ${ }^{20}$. Pathological examination demonstrates a range of findings such as dysplastic neurons, balloon cells, and lamination disorganization ${ }^{21,22}$. FCD can occur throughout the brain, but it is has a predilection for the frontal and temporal lobes ${ }^{22}$. It is one the most common forms of focal developmental disorder diagnosed in patients with partial epilepsy, constituting approximately $25 \%$ of patients ${ }^{23,24}$. Of these patients, approximately $76 \%$ have medically refractory seizures ${ }^{25}$. For the majority of patients, the onset of epilepsy occurs within the first 11 years of life, with generalized tonic-clonic, tonic, simple partial and complex partial seizures ${ }^{22}$ High-resolution MRI plays a key role in the diagnosis of the disorder and typically shows blurring of the junction between gray and white matter, gyral thickening, and abnormal signal such as $\mathrm{T} 2$ prolongation in the underlying white matter ${ }^{11}$. 
Given the heterogeneity of the disorder, no single genetic abnormality has been identified as a cause.

\section{Disorders due to abnormal neuronal migration}

Successful neuronal migration involves several stages: initial departure of neuroblasts from the ventricular zone, motility for migration to the cortical plate, and finally arrest of migration at the appropriate layer. Disruptions at any of these stages results in MCD.

\section{Periventricular heterotopia}

Periventricular heterotopia $(\mathrm{PH})$ refers to nodules of neurons found along the ventricular wall of the lateral ventricles, with an apparently normal cerebral cortex. This condition most likely represents a disorder of the initiation of migration in a small subpopulation of neurons while the majority of neurons successfully migrate out to the cerebral cortex. Pathologically, the nodules consist of normal appearing neurons and glial cells, with myelinated fibers and gliosis $^{26}$.

Affected patients often develop various types of seizures as the presenting symptom. While some patients manifest with seizures during the first few years of life, the majority of patients present in adolescence. Approximately $90 \%$ of patients with $\mathrm{PH}$ have epilepsy ${ }^{27}$, which may be easily controlled or refractory. There is no clear relationship between the epilepsy severity and extent of nodular heterotopia. In general, these patients have normal intelligence. However some patients may have learning problems such as impaired reading fluency that is out of proportion to their intelligence ${ }^{28}$.

Brain imaging using MRI demonstrates the typical nodules along the ventricular walls (Figure 1C). The pattern of involvement can be used to help to distinguish those with Xlinked dominant versus those with autosomal recessive mutations. Patients with X-linked dominant mutations typically have bilateral, nearly contiguous periventricular nodular heterotopia with thinning of the corpus callosum and posterior fossa abnormalities, such as cerebellar hypoplasia, and enlarged cisterna magna ${ }^{29}$. On the other hand, patients with autosomal recessive mutations have microcephaly, slightly enlarged ventricles, and delayed myelination ${ }^{30}$. Symmetrical nodular heterotopia lining the ventricles are again seen and the overlying cortex may be thinned with abnormal gyri ${ }^{11}$.

PH can be caused by genetic mutations or it can be acquired due to extrinsic factors, such as infection, injury, or radiation ${ }^{31,32,33}$. So far, X-linked dominant mutations in FLNA (Filamin $A$ ) and autosomal recessive mutations in $A R F G E F 2$ ( $A D P$-ribosylation factor guanine exchange factor 2) are associated with PH (Table 1). FLNA is an actin-binding phosphoprotein that stabilizes the cytoskeleton and mediates focal adhesions along the ventricular epithelium ${ }^{34}$. ARFGEF2 encodes for the BIG2 protein which converts guanine diphosphate (GDP) to guanine triphosphate (GTP) and thereby activates the ADPribosylation factors (ARFs). ARFs regulate vesicle trafficking and the transport of molecules from the interior of the cell to its surface, where they may attach and interact with other substances, or be secreted by the cell. In this respect, $A R F G E F 2$ may assist in the transport of FLNA to the cell surface. FLNA may subsequently be required for the initial attachment of neurons onto the radial glial scaffolding prior to migration from the ventricular zone ${ }^{35}$. Failure of migratory neurons to attach onto the radial glia could lead to heterotopia formation. Alternatively, both proteins are highly expressed along the neuroepithelial lining, and likely influence cell adhesion. Loss of neuroependymal integrity, similar to that seen with cobblestone lissencephaly, could lead to nodule formation along the lateral ventricles ${ }^{35}$. 
Additional insight into the pathogenic mechanisms underlying this cortical malformation has been gained from mice that develop periventricular heterotopia. Sarkisian and colleagues recently reported that loss of MEKK4, a MAP kinase that regulates the Stress-activated Protein Kinase Activator SEK-1, results in heterotopia formation in mice ${ }^{36}$. Interestingly, phosphorylation of FLNA at Ser2152 depends on MEKK4/SEK1 signaling and phosphorylation at this site regulates FLNA localization at the cell membrane. Other studies have shown that the hyh (hydrocephalus with hop gait) mouse phenotype is due to a mutation in the Napa gene, which encodes for the vesicle trafficking protein aSnap ${ }^{37}$. Loss of aSnap function leads to denudation of the neuroepithelium and heterotopia formation ${ }^{38}$ (personal observations). The aSnap protein is involved in SNAP receptor (SNARE)mediated vesicle fusion and thus, similar to $A R F G E F 2$ mutations in humans, suggesting that it plays a role in vesicle trafficking in $\mathrm{PH}$ formation. Finally, recent studies have suggested that the actin regulating RhoGTPase Cdc42 can disrupt the neuroependymal lining, vesicle trafficking of polarized protein, and lead to heterotopic neurons along the ventricle 39,40 . As actin is required for some forms of vesicle trafficking, it is possible that disruption of genes which are directly or indirectly linked to vesicle transport may be responsible for $\mathrm{PH}$ formation.

\section{Subcortical band heterotopia}

Subcortical band heterotopia, also known as "double cortex" syndrome, refers to a band of subcortical heterotopia neurons, located midway between the ventricles and the cerebral corte $^{41}$. The disorder is seen primarily in females and typically causes varying degrees of mental retardation and almost all of them have epilepsy. Approximately two thirds of patients with epilepsy ultimately develop intractable seizures ${ }^{42}$.

MRI of the brain in subcortical band heterotopia demonstrates two parallel layers of gray matter: a thin outer ribbon and a thick inner band, separated by a very thin layer of white matter between them (Figure 1D). The severity of epilepsy and developmental delay is directly correlated with the degree of migration arrest, as indicated by the thickness of the subcortical band heterotopia ${ }^{43}$.

Subcortical band heterotopia is caused by mutations in the microtubule-associated $D C X$ gene. The DCX protein is thought to direct neuronal migration by regulating the organization and stability of microtubules, necessary for neuronal motility. The malformation is seen only in females, as the gene is found on the X-chromosome. Since there are two $\mathrm{X}$ chromosomes in females, after $\mathrm{X}$-inactivation, only some neurons lose doublecortin function. These neurons with the mutant $D C X$ gene fail to migrate into the cortex and thus form the underlying heterotopic band, while neurons which express the normal gene successfully migrate out to the cortical plate. Males with $D C X$ mutations develop classical lissencephaly.

\section{Classical (Type I) Lisssencephaly}

Lissencephaly refers to "smooth brain" in which there is loss of the normal gyri and sulci of the brain. The severity of the malformation may range from agyria and pachygyria, to subcortical band heterotopia with a relatively normal gyral pattern. The cortex lacks the normal lamination and consists of only 4 layers instead of the typical 6 layers. Patients usually have severe mental retardation, epilepsy, and often also have microcephaly.

Several genes have been identified giving rise to classical lissencephaly: LIS1 (Lissencephaly1, autosomal dominant $)^{44}, D C X$ (Doublecortin, X-linked dominant) ${ }^{45}$, TUBA1A (Tubulin alpha 1A, autosomal dominant $)^{46,47}, A R X$ (Aristaless, X-linked dominant) ${ }^{48}$. and RELN (Reelin, autosomal recessive) ${ }^{48}$ (Table 1). Some characteristic 
differences in the clinical and radiographic presentation of these different lissencephaly disorders help to differentiate the causative genes.

Mutations in the LIS1, DCX, and TUBA1A generally cause similar clinical phenotypes, including microcephaly, mental retardation, with or without epilepsy, and motor deficits. The severity of isolated lissencephaly may be related to the type and location of the mutation ${ }^{49}$. Complete deletions of the LIS 1 and contiguous genes on chromosome 17p13.3 cause Miller-Dieker Syndrome (MDS). MDS is characterized by lissencephaly with additional distinct facial features, including prominent forehead, bitemporal hollowing, short nose with upturned nares, protuberant upper lip, and small jaw ${ }^{50,51}$. Mutations in $A R X$ cause the X-linked lissencephaly syndrome with ambiguous genitalia (XLAG) ${ }^{52}$. These patients have neonatal-onset epilepsy, hypothalamic dysfunction causing temperature dysregulation, chronic diarrhea, and ambiguous genitalia (micropenis and cryptorchidism) ${ }^{53}$. Mutations in RELN give rise to seizures, developmental delay and hypotonia. Moreover, the loss of cerebellar organization likely contributes to ataxia.

MRI of the brain in classical lissencephaly demonstrates an hour-glass configuration with areas of pachygyria and agyria and a shallow Sylvian fissure (Figure 1E). Differences in the location of involvement may be used to differentiate between LIS1 and DCX mutations ${ }^{11,54}$. The parietal and occipital regions are more severely affected in patients with LISI mutations, whereas the frontal and temporal regions are more severely affected in patients with $D C X$ mutations. MRI of the brain in patients with TUBA1A mutations demonstrate pachygyria or agyria, cerebellar hypoplasia with particular involvement of the inferior vermis, brainstem hypolasia, partial or complete agenesis of the corpus callosum, and ventricular dilatation ${ }^{46,47}$. Additionally, the posterior gyral malformations were more severe than the anterior regions, creating a posterior-anterior gradient. In individuals harboring $A R X$ mutations, the lissencephaly is again worse posteriorly than anteriorly (posterior agyria and anterior pachygyria) and there is absence of the corpus callosum by MRI. The cortex is moderately thickened $(5-10 \mathrm{~mm})$ with white matter signal abnormalities as well as a cystic or fragmented basal ganglia ${ }^{52,48}$. Finally in RELN mutations, the lissencephaly is associated with cerebellar hypoplasia and hippocampal and brainstem abnormalities.

Both LIS1 and DCX proteins appear to be regulators of microtubules, which are a part of the cytoskeleton of a cell, regulating cellular shape and motility. The DCX protein interacts with microtubules and contributes to their stability $41,55,56$. The LIS1 protein also likely interacts with microtubule-binding proteins and regulates neuronal migration by binding microtubules and assisting with the forward translocation of the cell soma toward the leading edge of the migrating cell 57,58 . Neurons which are heterozygous for the LIS1 mutation have reduced cell motility ${ }^{57}$. Disruption of microtubule function through LIS1 mutations also interferes with spindle orientation and mitosis ${ }^{18,59}$. This interruption in cell proliferation may contribute to the microcephaly seen in this disorder, as well as the ectopic localization of a heterogeneous population of differentiated neurons within the deep layers of the lissencephalic cortex ${ }^{59}$.

The TUBA1A gene encodes for brain-specific alpha tubulin. Alpha and beta tubulins are the main component of microtubules required for cell movement. Human mutations in $T U B A 1 A$ are thought to affect the folding of tubulin heterodimers and also influence interactions with proteins that bind microtubules (doublecortin and kinesin KIF1A) ${ }^{60}$. Given that microtubules play an important role in neuronal migration, it would be reasonable to postulate that disruption of microtubular function could lead to deficits in the motility of neuronal progenitor cells and lissencephaly ${ }^{46,47}$. 
$A R X$ is a homeobox gene which is expressed in the ganglionic eminences and the neocortical ventricular zone ${ }^{61}$. In mice with $A R X$ mutations, there is an accumulation of immature neurons in lateral and medial ganglionic eminences and both radial and tangential migration toward the cortex and striatum are significantly reduced ${ }^{61}$. Impaired differentiation of cortical GABAergic interneurons is also observed in those neurons harboring the mutation. In addition to lissencephaly, mutations in the $A R X$ gene cause a variety of other neurologic conditions including X-linked West syndrome ${ }^{62}, \mathrm{X}$-linked mental retardation ${ }^{63}$, myoclonic epilepsy ${ }^{62}$, and Partington disease (dystonia, epilepsy and mental retardation) ${ }^{64}$. As homeobox genes initiate a cascade of cellular events, it is difficult to ascertain which particular pathways cause the underlying lissencephaly. However, the $A R X$ gene clearly plays an important role in proliferation of neural precursors and differentiation of the forebrain.

Appropriate cell migration relies on proper intracellular and extracellular molecular signals. LIS1, DCX, and TUBA1A mutations seem to affect the intrinsic motility of neural progenitor cells. Extrinsic signals and cellular interactions also play an important role in guiding appropriate cellular migration. Reelin is a signaling glycoprotein secreted by the early neurons on the surface of the cerebral cortex known as the Cajal Retzius cells. Activation of the Reelin signaling pathway is thought to be essential for proper positioning of migratory neurons into the appropriate lamina of the cortex ${ }^{65}$. In mice, loss of reelin causes disorganized lamination of the cerebral cortex ${ }^{66}$, whereby the layers are inverted, with earlier born cells forming the superficial layers of cortex and later born neurons forming the deeper layers.

While disruption in microtubule and microtubule associated proteins such as doublecortin, lissencephaly 1 and alpha-tubulin would understandably alter neuronal motility and migration, the potential role of reelin in giving rise to lissencephaly is not entirely clear. However, phenotypic similarities between the reeler mouse mutant and genetically modified mice null for cyclin dependent kinase $5(\mathrm{cdk} 5)^{67}$ or cdk5 activator p35 (p35 inverted layering) ${ }^{68}$ do suggest a shared pathway. Mice lacking $\mathrm{p} 35$, cdk5, or reelin all show disrupted lamination and inverted lamination. The Lis-1 interacting protein Ndel1 has been shown to be a cdk5 substrate, and to be involved in neuronal motility. Cdk5 is also a substrate for the microtubule associated protein tau ${ }^{69}$. Thus, cdk5 might connect Reelin signaling with other lissencephaly protein complexes such as the Ndel1-Lis1 complex to control microtubule dynamics and neuronal migration.

Inhibitory interneurons, or GABAergic neurons, constitute approximately $20-30 \%$ of all cortical neurons. As mentioned earlier, they originate from the medial, lateral and caudal ganglionic eminences, migrate tangentially at first, and then radially before distribution within the different layers of the cerebral cortex. These interneurons are classified into subtypes and animal studies have shown that the $L h x 6$ gene is preferentially expressed in some tangentially migrating GABAergic interneurons. The Lhx6 gene encodes for one of the homeodomain transcription factors that regulate neuronal subtype specifications and cell fate decisions ${ }^{70}$. More recently, Liodis and colleagues demonstrated that $L h x 6$ plays an important role in the normal tangential and radial migration of these interneurons during embryogensesis $^{71}$.

\section{Disorders due to abnormal neuronal migration arrest}

\section{Cobblestone (Type II) lissencephaly}

Cobblestone lissencephaly, also known as type II lissencephaly, refers to the nodular appearance of the cerebral cortex caused by disorganization of the cortical layers, and over- 
migration of neurons through the pial surface of the brain into the leptomeninges. It is associated with various eye abnormalities and congenital muscular dystrophies.

Based on severity, cobblestone lissencephaly has been divided into three different classes. The mild form is seen in Fukuyama congenital muscular dystrophy (FCMD) that affects primarily the Japanese population ${ }^{72}$. Patients typically present with hypotonia and generalized weakness in infancy. The majority of patients are unable to walk unsupported ${ }^{73}$. Mental retardation is a universal finding and some patients also have epilepsy. The moderate form is seen in muscle-eye-brain disease (MEB) that primarily affects the Finnish population ${ }^{74}$. Early onset of severe myopia, glaucoma, optic disc pallor and retinal hypoplasia are the typical eye findings. Patients also have mental retardation, myoclonic jerks, and congenital muscular dystrophy. Finally, the more severe form of cobblestone lissencephaly is seen in Walker-Warburg Syndrome (WWS) which typically results in death within a few months after birth ${ }^{75}$. Ophthalmologic abnormalities include retinal dysplasia, microphthalmia, cataracts, and glaucoma. Again, congenital muscular dystrophy is a key feature.

Brain imaging using MRI demonstrates the typical cobblestone lissencephaly (Figure 1F) as well as a spectrum of CNS abnormalities of varying degrees of severity ${ }^{11}$. All of the abnormalities are most severe in Walker-Warburg syndrome. A "Z-shaped" hypoplastic brainstem is considered a key feature. Other typical MRI findings include abnormal signal in the white matter due to hypomyelination and polymicrogyria as seen in FCMD, which is particularly associated with frontal polymicrogyria with occipital cobblestone lissencephaly. Aqueductal stenosis with hydrocephalus, vermian hypogenesis, cerebellar agyriamicropolygyria, patchy abnormal white matter signal, and agenesis or hypogenesis of the corpus callosum can also be seen, as in MEB disease in the Finnish population ${ }^{76}$. WWS is the most severe form and may demonstrate all of the previously mentioned findings, as well as occipital encephalocele ${ }^{11}$.

Cobblestone lissencephaly follows an autosomal recessive inheritance pattern. Four associated genes have been identified: POMT1 (Protein-O-mannosyltransferase 1) and POMT2 (Protein-O-mannosyltransferase 2) for WWS, POMGnT1 (Protein O-mannose 1,2$N$-acetylglucosaminyltransferase) linked to chromosome 1p32-34 for the Finnish MEB disorder ${ }^{77,78}$, and Fukutin on chromosome 9q31for FCMD ${ }^{79}$ (Table 1). All of these genes are involved in the glycosylation of alpha dystroglycan, which are highly glycosylated proteins and act as receptors for the multiple extracellular matrix molecules that maintain stability of the cell surface. Mutations in these genes affect the O-glycosylation of alpha dystroglycan, thereby compromising the integrity of the dystrophy-associated extracellular matrix adhesion complex and lead to weakening of the structural integrity of the superficial marginal zone or the cortex. Migratory neurons are then able to "over-migrate" beyond this structural barrier onto the pial surface, forming the typical cobblestone, or bumpy surface.

Disruption in the basal lamina along the surface of the brain in mice similarly leads to a cobblestone phenotype in mice. Presenilin1 (PS1) is a transmembrane protein, located in the Golgi apparatus, and best known for its processing of amyloid precursor protein.

Presenilin1-deficient mice develop a cortical dysplasia resembling human cobblestone lissencephaly, with leptomeningeal fibrosis and migration of cortical-plate neurons beyond their normal position into the marginal zone and subarachnoid space. PS1 deficiency interferes with the ability of the leptomeningeal cells to support the Cajal-Retzius cells and maintain an intact pial basement membrane, resulting in both over migration of neurons and premature termination of neuronal migration of both radially migrating neurons and CajalRetzius neurons. Pathologic examinations reveal a loss of the Cajal-Retzius neurons within the marginal zone, depletion of the extracellular matrix protein reelin and chondroitin sulfate 
proteoglycans ${ }^{80}$. Another animal model to demonstrate the importance of the surface basement membrane utilizes isolated deletions of various basement membrane constituents or receptors, such as alpha 6 integrin, resulting in abnormal laminar organization of the brain and retina, with ectopic neuronal growth on the brain surface, similar to WWS ${ }^{81}$. Loss of integrin linked kinase in mice results in a similar lissencephalic phenotype ${ }^{82}$. Integrin linked kinase is a scaffold and kinase that links integrin receptors to the actin cytoskeleton and to signaling pathways involved in extracellular matrix deposition. Overall, disruption of mouse or human genes involved in basal lamina formation appear to be responsible for the development cobblestone lissencephaly.

\section{Disorders due to abnormal neuronal organization}

Cortical organization involves a process of synaptogenesis and neuronal maturation which are further refined via synapse pruning and apoptosis.

\section{Polymicrogyria and Schizencephaly}

Polymicrogyria refers to an excessive number of small gyri separated by shallow sulci, giving the surface of the cortex its characteristic lumpy appearance. Polymicrogyria can be focal or diffuse, unilateral or bilateral. Unilateral involvement may be associated with variable cognitive impairment, congenital hemiparesis, focal seizures ${ }^{83}$, and visual field defects ${ }^{84}$. Deletion of $22 \mathrm{q} 11.2$ has been found to be associated with polymicrogyria and seems to have a predisposition for the right hemisphere ${ }^{85}$.

Bilateral involvement of the cortex is frequently seen, with a symmetric or asymmetric distribution, affecting the frontal, fronto-parietal, parieto-occipital, perisylvian, and mesial occipital regions. There is a wide spectrum of clinical manifestations owing to the various locations that are involved. For example, bilateral frontoparietal polymicrogyria is associated with developmental delay, hypertonicity, ataxia, and refractory seizures ${ }^{86}$. Congenital bilateral perisylvian syndrome (CBPS) is one of the best described syndromes. Affected patients have pseudobulbar palsy, spastic quadriparesis, and epilepsy. Between $50-85 \%$ of patients develop seizures, ranging from atypical absence, tonic, atonic, and generalized tonic-clonic seizures ${ }^{87}$. Imaging of the brain using MRI demonstrates small irregular gyri and an indistinct gray and white matter junction ${ }^{11}$. The thickness of the cortex may be normal or abnormally thick or thin.

Familial patterns have been recognized in bilateral frontoparietal, bilateral perisylvian, and generalized polymicrogyria. Bilateral frontal and parietal polymicrogyria seem to be associated with mutations in the G-protein-coupled receptor gene $(G P R 56)^{88,89}$. Expression of this gene appears to be highest in the neuronal progenitor cells along the ventricular and subventricular zones. The assumption is that this gene plays a role in regional organization of the brain.

Schizencephaly is classified within the same group as polymicrogyria. Schizencephaly refers to a cleft extending from the cerebral cortex to the ventricle and is typically lined by polymicrogyric cortex. It is in fact considered to be an extreme form of polymicrogyria ${ }^{90}$. Schizencephaly can be unilateral or bilateral and tends involve the insular, precentral and postcentral regions ${ }^{11}$. Type I schizencephaly refers to "closed-lip" clefts or small defects that are fused. In contrast, type II schizencephaly refers to "open-lip" clefts or large defects which are filled with fluid. The neurologic manifestations of the disorder depend on the anatomic location and type of the abnormality. Patients with type I lesions tend to be mildly affected and have partial seizures or spastic hemiparesis. On the other hand, patients with type II defects (open cleft) tend to have severe developmental delay, microcephaly, seizures, and spasticity. In particular, those with bilateral involvement have spastic quadriparesis and 
severe cognitive impairment. Non CNS manifestations have also been reported, such as gastroschisis, and bowel atresias ${ }^{91}$. Radiographically, in addition to the schizencephaly seen on MRI, an absent or deficient septum pellucidum may be seen and is often associated with temporal or occipital clefts ${ }^{11}$. The gray matter lining the cleft is nodular, with a polymicrogyric appearance.

Familial cases have been identified and have helped to shed light on the genetic basis of the disorder $^{92}$. The inheritance pattern is still unclear although the mutations are thought to be autosomal dominant ${ }^{93}$. Initial reports suggest that EMX2 gene mutations may be associated with type II schizencephaly ${ }^{92}$; however, this finding needs to be confirmed in additional studies.

\section{Management}

As discussed above, the phenotype of MCD is extremely heterogeneous and the severity of the neurologic deficits can be quite varied, ranging from relatively mild to severe. Not surprisingly, given the abnormalities in the cerebral cortex, patients frequently suffer from epilepsy which may be refractory to pharmacologic treatment. Those patients who fail 3 antiepileptic medications are less likely to have their seizures controlled with additional trials of medications and epilepsy surgery should be considered. In addition to better seizure control, the goals of the surgery may include improvement of cognitive and psychosocial function, and ultimately better quality of life. The goals obviously need to be balanced against the risk of potential functional deficits that might result from the surgery. A detailed step-wise presurgical evaluation must be undertaken to evaluate whether the patient is an appropriate surgical candidate.

Vagus nerve stimulation (VNS) was approved in 1997 as adjunct treatment of refractory epilepsy for patients age 12 and older ${ }^{94}$. The device is implanted surgically and delivers stimulation to the vagus nerve at various frequencies, but the exact mechanism is unknown. Up to $43 \%$ of patients may experience a greater than $50 \%$ reduction of seizure frequency at the end of 2 years ${ }^{95}$. Thus, VNS is an option for patients who may not be good surgical candidates or who have failed surgery.

Aside from seizure control, management of these patients requires a multidisciplinary team approach to address both the medical and the psychosocial aspects of the disorder. As the genetic basis for many of these disorders have been identified, genetic testing may be possible for the patient as well as the family members. Appropriate genetic counseling may be an important aspect of management particularly for parents are planning to have more children.

\section{Conclusion}

With recent advances in neuroimaging, there is a significant increase in the recognition of MCD as a cause of epilepsy and neurologic dysfunction. Research in delineating the genetic and molecular basis of these disorders has given us greater insight into the pathogenesis of not only the malformations, but also the processes involved in normal cortical development. From a clinical perspective, improved diagnosis of MCD will allow for better treatment of symptomatic epilepsy (including offering surgical options when appropriate). The possibility of genetic testing and genetic counseling for families also play an important role in the overall management of patients with MCD. Hopefully, further research in elucidating the genetic and pathophysiologic mechanisms of MCD will lead the development of potential treatment strategies at various stages of development. 


\section{Acknowledgments}

Sponsorship: VLS is a Beckman Young Investigator and a recipient of the Doris Duke Clinical Scientist Development Award.

\section{References}

1. Kuzniecky RI. Magnetic resonance imaging in developmental disorders of the cerebral cortex. Epilepsia. 1994; 35(Suppl 6):S44-56. [PubMed: 8206014]

2. Barkovich AJ, Kuzniecky RI, Jackson GD, Guerrini R, Dobyns WB. A developmental and genetic classification for malformations of cortical development. Neurology. 2005; 65:1873-1887. [PubMed: 16192428]

3. Lombroso CT. Can early postnatal closed head injury induce cortical dysplasia. Epilepsia. 2000; 41:245-253. [PubMed: 10691125]

4. Sarnat HB. Disturbances of late neuronal migrations in the perinatal period. American journal of diseases of children (1960). 1987; 141:969-980. [PubMed: 2441596]

5. Chenn A, McConnell SK. Cleavage orientation and the asymmetric inheritance of Notch1 immunoreactivity in mammalian neurogenesis. Cell. 1995; 82:631-641. [PubMed: 7664342]

6. Anderson SA, Eisenstat DD, Shi L, Rubenstein JL. Interneuron migration from basal forebrain to neocortex: dependence on Dlx genes. Science. 1997; 278:474-476. [PubMed: 9334308]

7. Anderson S, Mione M, Yun K, Rubenstein JL. Differential origins of neocortical projection and local circuit neurons: role of Dlx genes in neocortical interneuronogenesis. Cereb Cortex. 1999; 9:646-654. [PubMed: 10498283]

8. Kriegstein AR, Noctor SC. Patterns of neuronal migration in the embryonic cortex. Trends in neurosciences. 2004; 27:392-399. [PubMed: 15219738]

9. Metin C, Baudoin JP, Rakic S, Parnavelas JG. Cell and molecular mechanisms involved in the migration of cortical interneurons. The European journal of neuroscience. 2006; 23:894-900. [PubMed: 16519654]

10. Sidman RL, Rakic P. Neuronal migration, with special reference to developing human brain: a review. Brain Res. 1973; 62:1-35. [PubMed: 4203033]

11. Osborn, AG. Brain. 1. Vol. 1. Salt Lake City, Utah: Amirsys; 2004. Diagnostic imaging. various pagings

12. Zhong X, Pfeifer GP, Xu X. Microcephalin encodes a centrosomal protein. Cell cycle (Georgetown, Tex. 2006; 5:457-458.

13. Trimborn M, Bell SM, Felix C, et al. Mutations in microcephalin cause aberrant regulation of chromosome condensation. American journal of human genetics. 2004; 75:261-266. [PubMed: 15199523]

14. Zhong X, Liu L, Zhao A, Pfeifer GP, Xu X. The abnormal spindle-like, microcephaly-associated (ASPM) gene encodes a centrosomal protein. Cell cycle (Georgetown, Tex. 2005; 4:1227-1229.

15. do Carmo Avides M, Glover DM. Abnormal spindle protein, Asp, and the integrity of mitotic centrosomal microtubule organizing centers. Science. 1999; 283:1733-1735. [PubMed: 10073938]

16. Bond J, Roberts E, Springell K, et al. A centrosomal mechanism involving CDK5RAP2 and CENPJ controls brain size. Nature genetics. 2005; 37:353-355. [PubMed: 15793586]

17. Hung LY, Tang CJ, Tang TK. Protein 4.1 R-135 interacts with a novel centrosomal protein (CPAP) which is associated with the gamma-tubulin complex. Molecular and cellular biology. 2000; 20:7813-7825. [PubMed: 11003675]

18. Feng Y, Walsh CA. Mitotic spindle regulation by Nde1 controls cerebral cortical size. Neuron. 2004; 44:279-293. [PubMed: 15473967]

19. Tinkle BT, Schorry EK, Franz DN, Crone KR, Saal HM. Epidemiology of hemimegalencephaly: a case series and review. Am J Med Genet A. 2005; 139:204-211. [PubMed: 16283674]

20. Sisodiya SM. Malformations of cortical development: burdens and insights from important causes of human epilepsy. Lancet Neurol. 2004; 3:29-38. [PubMed: 14693109]

21. Taylor DC, Falconer MA, Bruton CJ, Corsellis JA. Focal dysplasia of the cerebral cortex in epilepsy. J Neurol Neurosurg Psychiatry. 1971; 34:369-387. [PubMed: 5096551] 
22. Fauser S, Huppertz HJ, Bast T, et al. Clinical characteristics in focal cortical dysplasia: a retrospective evaluation in a series of 120 patients. Brain. 2006; 129:1907-1916. [PubMed: 16714316]

23. Kuzniecky R, Murro A, King D, et al. Magnetic resonance imaging in childhood intractable partial epilepsies: pathologic correlations. Neurology. 1993; 43:681-687. [PubMed: 8469322]

24. Tassi L, Colombo N, Garbelli R, et al. Focal cortical dysplasia: neuropathological subtypes, EEG, neuroimaging and surgical outcome. Brain. 2002; 125:1719-1732. [PubMed: 12135964]

25. Semah F, Picot MC, Adam C, et al. Is the underlying cause of epilepsy a major prognostic factor for recurrence? Neurology. 1998; 51:1256-1262. [PubMed: 9818842]

26. Tassi L, Colombo N, Cossu M, et al. Electroclinical, MRI and neuropathological study of 10 patients with nodular heterotopia, with surgical outcomes. Brain. 2005; 128:321-337. [PubMed: 15618282]

27. Dubeau F, Tampieri D, Lee N, et al. Periventricular and subcortical nodular heterotopia. A study of 33 patients. Brain. 1995; 118(Pt 5):1273-1287. [PubMed: 7496786]

28. Chang BS, Ly J, Appignani B, et al. Reading impairment in the neuronal migration disorder of periventricular nodular heterotopia. Neurology. 2005; 64:799-803. [PubMed: 15753412]

29. Fox JW, Lamperti ED, Eksioglu YZ, et al. Mutations in filamin 1 prevent migration of cerebral cortical neurons in human periventricular heterotopia. Neuron. 1998; 21:1315-1325. [PubMed: 9883725]

30. Sheen VL, Ganesh VS, Topcu M, et al. Mutations in ARFGEF2 implicate vesicle trafficking in neural progenitor proliferation and migration in the human cerebral cortex. Nature genetics. 2004; 36:69-76. [PubMed: 14647276]

31. Ferrer I, Santamaria J, Alcantara S, Zujar MJ, Cinos C. Neuronal ectopic masses induced by prenatal irradiation in the rat. Virchows Archiv. 1993; 422:1-6. [PubMed: 8438554]

32. Wetzburger CL, Van Regemorter N, Szliwowski HB, Abramowicz MJ, Van Bogaert P. Gray matter heterotopia and acute necrotizing encephalopathy in trichothiodystrophy. Pediatr Neurol. 1998; 19:392-394. [PubMed: 9880148]

33. Montenegro MA, Guerreiro MM, Lopes-Cendes I, Guerreiro CA, Cendes F. Interrelationship of genetics and prenatal injury in the genesis of malformations of cortical development. Arch Neurol. 2002; 59:1147-1153. [PubMed: 12117363]

34. Lu J, Tiao G, Folkerth R, Hecht J, Walsh C, Sheen V. Overlapping expression of ARFGEF2 and Filamin A in the neuroependymal lining of the lateral ventricles: insights into the cause of periventricular heterotopia. The Journal of comparative neurology. 2006; 494:476-484. [PubMed: 16320251]

35. Lu J, Sheen V. Periventricular heterotopia. Epilepsy Behav. 2005; 7:143-149. [PubMed: 15996530]

36. Sarkisian MR, Bartley CM, Chi H, et al. MEKK4 signaling regulates filamin expression and neuronal migration. Neuron. 2006; 52:789-801. [PubMed: 17145501]

37. Chae TH, Kim S, Marz KE, Hanson PI, Walsh CA. The hyh mutation uncovers roles for alpha Snap in apical protein localization and control of neural cell fate. Nature genetics. 2004 ; 36:264270. [PubMed: 14758363]

38. Jimenez AJ, Tome M, Paez P, et al. A programmed ependymal denudation precedes congenital hydrocephalus in the hyh mutant mouse. Journal of neuropathology and experimental neurology. 2001; 60:1105-1119. [PubMed: 11706940]

39. Cappello S, Attardo A, Wu X, et al. The Rho-GTPase cdc42 regulates neural progenitor fate at the apical surface. Nature neuroscience. 2006; 9:1099-1107.

40. Chen L, Liao G, Yang L, et al. Cdc42 deficiency causes Sonic hedgehog-independent holoprosencephaly. Proceedings of the National Academy of Sciences of the United States of America. 2006; 103:16520-16525. [PubMed: 17050694]

41. Gleeson JG, Lin PT, Flanagan LA, Walsh CA. Doublecortin is a microtubule-associated protein and is expressed widely by migrating neurons. Neuron. 1999; 23:257-271. [PubMed: 10399933]

42. Guerrini R, Carrozzo R. Epilepsy and genetic malformations of the cerebral cortex. American journal of medical genetics. 2001; 106:160-173. [PubMed: 11579436] 
43. Barkovich AJ, Guerrini R, Battaglia G, et al. Band heterotopia: correlation of outcome with magnetic resonance imaging parameters. Ann Neurol. 1994; 36:609-617. [PubMed: 7524438]

44. Reiner O, Carrozzo R, Shen Y, et al. Isolation of a Miller-Dieker lissencephaly gene containing G protein beta-subunit-like repeats. Nature. 1993; 364:717-721. [PubMed: 8355785]

45. Gleeson JG, Allen KM, Fox JW, et al. Doublecortin, a brain-specific gene mutated in human Xlinked lissencephaly and double cortex syndrome, encodes a putative signaling protein. Cell. 1998; 92:63-72. [PubMed: 9489700]

46. Poirier K, Keays DA, Francis F, et al. Large spectrum of lissencephaly and pachygyria phenotypes resulting from de novo missense mutations in tubulin alpha 1A (TUBA1A). Human mutation. 2007; 28:1055-1064. [PubMed: 17584854]

47. Keays DA, Tian G, Poirier K, et al. Mutations in alpha-tubulin cause abnormal neuronal migration in mice and lissencephaly in humans. Cell. 2007; 128:45-57. [PubMed: 17218254]

48. Bonneau D, Toutain A, Laquerriere A, et al. X-linked lissencephaly with absent corpus callosum and ambiguous genitalia (XLAG): clinical, magnetic resonance imaging, and neuropathological findings. Ann Neurol. 2002; 51:340-349. [PubMed: 11891829]

49. Cardoso C, Leventer RJ, Matsumoto N, et al. The location and type of mutation predict malformation severity in isolated lissencephaly caused by abnormalities within the LIS 1 gene. Human molecular genetics. 2000; 9:3019-3028. [PubMed: 11115846]

50. Dobyns WB, Reiner O, Carrozzo R, Ledbetter DH. Lissencephaly. A human brain malformation associated with deletion of the LIS1 gene located at chromosome 17p13. Jama. 1993; 270:2838_ 2842. [PubMed: 7907669]

51. Dobyns WB, Curry CJ, Hoyme HE, Turlington L, Ledbetter DH. Clinical and molecular diagnosis of Miller-Dieker syndrome. American journal of human genetics. 1991; 48:584-594. [PubMed: 1671808]

52. Dobyns WB, Berry-Kravis E, Havernick NJ, Holden KR, Viskochil D. X-linked lissencephaly with absent corpus callosum and ambiguous genitalia. American journal of medical genetics. 1999; 86:331-337. [PubMed: 10494089]

53. Kitamura K, Yanazawa M, Sugiyama N, et al. Mutation of ARX causes abnormal development of forebrain and testes in mice and X-linked lissencephaly with abnormal genitalia in humans. Nature genetics. 2002; 32:359-369. [PubMed: 12379852]

54. Dobyns WB, Truwit CL, Ross ME, et al. Differences in the gyral pattern distinguish chromosome 17-linked and X-linked lissencephaly. Neurology. 1999; 53:270-277. [PubMed: 10430413]

55. Francis F, Koulakoff A, Boucher D, et al. Doublecortin is a developmentally regulated, microtubule-associated protein expressed in migrating and differentiating neurons. Neuron. 1999; 23:247-256. [PubMed: 10399932]

56. Horesh D, Sapir T, Francis F, et al. Doublecortin, a stabilizer of microtubules. Human molecular genetics. 1999; 8:1599-1610. [PubMed: 10441322]

57. Faulkner NE, Dujardin DL, Tai CY, et al. A role for the lissencephaly gene LIS1 in mitosis and cytoplasmic dynein function. Nature cell biology. 2000; 2:784-791.

58. Niethammer M, Smith DS, Ayala R, et al. NUDEL is a novel Cdk5 substrate that associates with LIS1 and cytoplasmic dynein. Neuron. 2000; 28:697-711. [PubMed: 11163260]

59. Sheen VL, Ferland RJ, Harney M, et al. Impaired proliferation and migration in human MillerDieker neural precursors. Ann Neurol. 2006; 60:137-144. [PubMed: 16642511]

60. Moores CA, Perderiset M, Francis F, Chelly J, Houdusse A, Milligan RA. Mechanism of microtubule stabilization by doublecortin. Molecular cell. 2004; 14:833-839. [PubMed: 15200960]

61. Colombo E, Collombat P, Colasante G, et al. Inactivation of Arx, the murine ortholog of the Xlinked lissencephaly with ambiguous genitalia gene, leads to severe disorganization of the ventral telencephalon with impaired neuronal migration and differentiation. J Neurosci. 2007; 27:47864798. [PubMed: 17460091]

62. Stromme P, Mangelsdorf ME, Shaw MA, et al. Mutations in the human ortholog of Aristaless cause X-linked mental retardation and epilepsy. Nature genetics. 2002; 30:441-445. [PubMed: 11889467] 
63. Bienvenu T, Poirier K, Friocourt G, et al. ARX, a novel Prd-class-homeobox gene highly expressed in the telencephalon, is mutated in X-linked mental retardation. Human molecular genetics. 2002; 11:981-991. [PubMed: 11971879]

64. Frints SG, Borghgraef M, Froyen G, Marynen P, Fryns JP. Clinical study and haplotype analysis in two brothers with Partington syndrome. American journal of medical genetics. 2002; 112:361368. [PubMed: 12376938]

65. Dulabon L, Olson EC, Taglienti MG, et al. Reelin binds alpha3beta1 integrin and inhibits neuronal migration. Neuron. 2000; 27:33-44. [PubMed: 10939329]

66. Caviness VS Jr. Neocortical histogenesis in normal and reeler mice: a developmental study based upon [3H]thymidine autoradiography. Brain Res. 1982; 256:293-302. [PubMed: 7104762]

67. Ohshima T, Ward JM, Huh CG, et al. Targeted disruption of the cyclin-dependent kinase 5 gene results in abnormal corticogenesis, neuronal pathology and perinatal death. Proceedings of the National Academy of Sciences of the United States of America. 1996; 93:11173-11178. [PubMed: 8855328]

68. Chae T, Kwon YT, Bronson R, Dikkes P, Li E, Tsai LH. Mice lacking p35, a neuronal specific activator of Cdk5, display cortical lamination defects, seizures, and adult lethality. Neuron. 1997; 18:29-42. [PubMed: 9010203]

69. Olson EC, Walsh CA. Smooth, rough and upside-down neocortical development. Current opinion in genetics \& development. 2002; 12:320-327. [PubMed: 12076676]

70. Grigoriou M, Tucker AS, Sharpe PT, Pachnis V. Expression and regulation of Lhx6 and Lhx7, a novel subfamily of LIM homeodomain encoding genes, suggests a role in mammalian head development. Development (Cambridge, England). 1998; 125:2063-2074.

71. Liodis P, Denaxa M, Grigoriou M, Akufo-Addo C, Yanagawa Y, Pachnis V. Lhx6 activity is required for the normal migration and specification of cortical interneuron subtypes. J Neurosci. 2007; 27:3078-3089. [PubMed: 17376969]

72. Fukuyama Y, Osawa M, Suzuki H. Congenital progressive muscular dystrophy of the Fukuyama type - clinical, genetic and pathological considerations. Brain Dev. 1981; 3:1-29. [PubMed: 7258547]

73. Yoshioka M, Kuroki S. Clinical spectrum and genetic studies of Fukuyama congenital muscular dystrophy. American journal of medical genetics. 1994; 53:245-250. [PubMed: 7856660]

74. Santavuori P, Somer H, Sainio K, et al. Muscle-eye-brain disease (MEB). Brain Dev. 1989; 11:147-153. [PubMed: 2751061]

75. Dobyns WB, Pagon RA, Armstrong D, et al. Diagnostic criteria for Walker-Warburg syndrome. American journal of medical genetics. 1989; 32:195-210. [PubMed: 2494887]

76. Towfighi J, Sassani JW, Suzuki K, Ladda RL. Cerebro-ocular dysplasia-muscular dystrophy (COD-MD) syndrome. Acta neuropathologica. 1984; 65:110-123. [PubMed: 6441438]

77. Cormand B, Avela K, Pihko H, et al. Assignment of the muscle-eye-brain disease gene to 1p32p34 by linkage analysis and homozygosity mapping. American journal of human genetics. 1999; 64:126-135. [PubMed: 9915951]

78. Yoshida A, Kobayashi K, Manya H, et al. Muscular dystrophy and neuronal migration disorder caused by mutations in a glycosyltransferase, POMGnT1. Developmental cell. 2001; 1:717-724. [PubMed: 11709191]

79. Toda T, Ikegawa S, Okui K, et al. Refined mapping of a gene responsible for Fukuyama-type congenital muscular dystrophy: evidence for strong linkage disequilibrium. American journal of human genetics. 1994; 55:946-950. [PubMed: 7977357]

80. Hartmann D, De Strooper B, Saftig P. Presenilin-1 deficiency leads to loss of Cajal-Retzius neurons and cortical dysplasia similar to human type 2 lissencephaly. Curr Biol. 1999; 9:719-727. [PubMed: 10421573]

81. Georges-Labouesse E, Mark M, Messaddeq N, Gansmuller A. Essential role of alpha 6 integrins in cortical and retinal lamination. Curr Biol. 1998; 8:983-986. [PubMed: 9742403]

82. Niewmierzycka A, Mills J, St-Arnaud R, Dedhar S, Reichardt LF. Integrin-linked kinase deletion from mouse cortex results in cortical lamination defects resembling cobblestone lissencephaly. $\mathrm{J}$ Neurosci. 2005; 25:7022-7031. [PubMed: 16049178] 
83. Caraballo RH, Cersosimo RO, Mazza E, Fejerman N. Focal polymicrogyria in mother and son. Brain Dev. 2000; 22:336-339. [PubMed: 10891642]

84. Chang BS, Apse KA, Caraballo R, et al. A familial syndrome of unilateral polymicrogyria affecting the right hemisphere. Neurology. 2006; 66:133-135. [PubMed: 16401865]

85. Robin NH, Taylor CJ, McDonald-McGinn DM, et al. Polymicrogyria and deletion 22q11.2 syndrome: window to the etiology of a common cortical malformation. Am J Med Genet A. 2006; 140:2416-2425. [PubMed: 17036343]

86. Straussberg R, Gross S, Amir J, Gadoth N. A new autosomal recessive syndrome of pachygyria. Clinical genetics. 1996; 50:498-501. [PubMed: 9147882]

87. Kuzniecky R, Andermann F, Guerrini R. Congenital bilateral perisylvian syndrome: study of 31 patients. The CBPS Multicenter Collaborative Study. Lancet. 1993; 341:608-612. [PubMed: 8094839]

88. Piao X, Basel-Vanagaite L, Straussberg R, et al. An autosomal recessive form of bilateral frontoparietal polymicrogyria maps to chromosome 16q12.2-21. American journal of human genetics. 2002; 70:1028-1033. [PubMed: 11845408]

89. Piao X, Chang BS, Bodell A, et al. Genotype-phenotype analysis of human frontoparietal polymicrogyria syndromes. Ann Neurol. 2005; 58:680-687. [PubMed: 16240336]

90. Barkovich AJ, Kjos BO. Schizencephaly: correlation of clinical findings with MR characteristics. Ajnr. 1992; 13:85-94. [PubMed: 1595498]

91. Curry CJ, Lammer EJ, Nelson V, Shaw GM. Schizencephaly: heterogeneous etiologies in a population of 4 million California births. Am J Med Genet A. 2005; 137:181-189. [PubMed: 16059942]

92. Brunelli S, Faiella A, Capra V, et al. Germline mutations in the homeobox gene EMX2 in patients with severe schizencephaly. Nature genetics. 1996; 12:94-96. [PubMed: 8528262]

93. Jansen A, Andermann E. Genetics of the polymicrogyria syndromes. Journal of medical genetics. 2005; 42:369-378. [PubMed: 15863665]

94. Schachter SC, Saper CB. Vagus nerve stimulation. Epilepsia. 1998; 39:677-686. [PubMed: 9670894]

95. Ben-Menachem E. Vagus-nerve stimulation for the treatment of epilepsy. Lancet Neurol. 2002; 1:477-482. [PubMed: 12849332] 

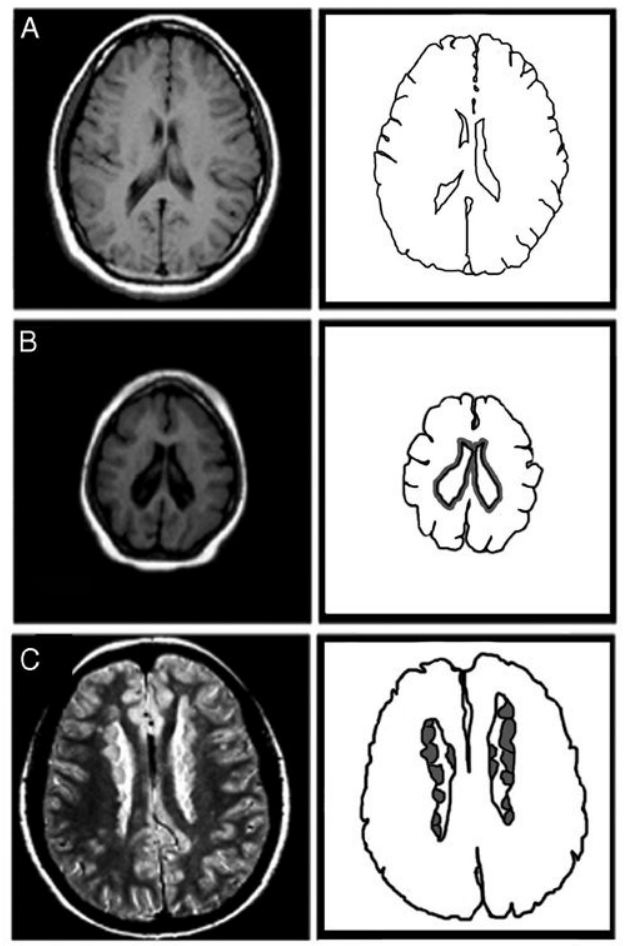
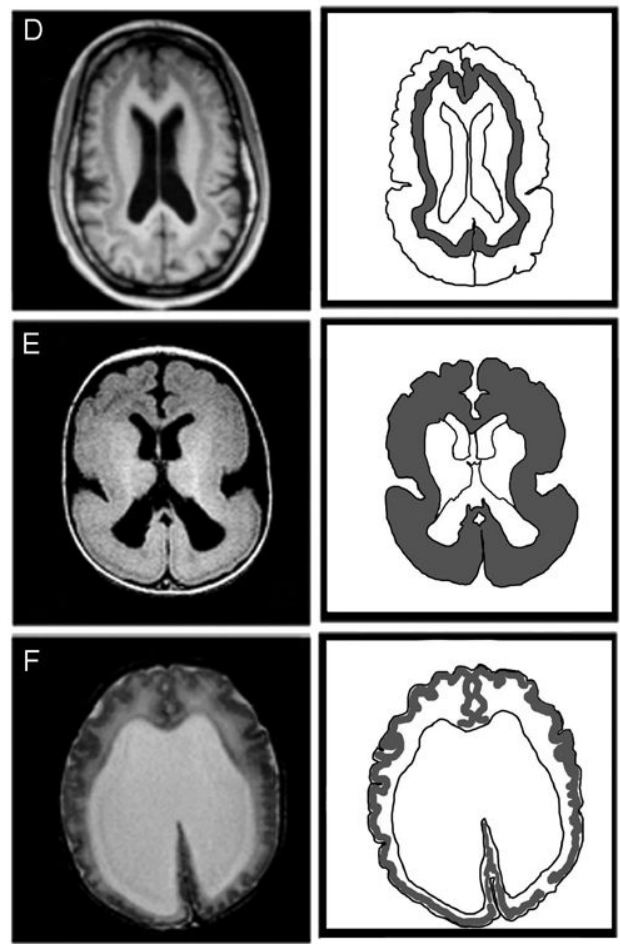

Figure 1.

A. Normal brain. Axial T1-weighted MRI. Camera lucida rendering of the normal brain is to the right. B. Microcephaly. Axial T1-weighted MRI in a patient with a $A S P M$ mutation. Camera lucida rendering to the right shows the region of disruption (grey) along the ventricular zone giving rise to microcephaly. C. Periventricular heterotopia. Axial T2weighted brain MRI of a patient with a FLNA mutation. Note the nodules of heterotopic gray matter lining the lateral ventricles bilaterally. Camera lucida rendering to the right shows regions of disruption (grey) involving gray matter nodules along the lining of the ventricle. D. Subcortical band heterotopia. Axial T1-weighted brain MRI of a patient with a $D C X$ mutation. Note the thick band of gray matter running deep and parallel to the thinned outer cortex. A thin band of white matter separates the outer cortex and the inner subcortical band of heterotopic neurons. Camera lucida rendering to the right shows the region of disruption (grey) involving a band of neurons midway between the cortical surface and ventricles. E. Classical lissencephaly (Type I lissencephaly). Axial T1-weighted brain MRI of type I or classic lissencephaly in a patient harboring a LIS1 mutation. The brain has an "hour-glass" appearance with agyria and pachygyria. Note the greater severity of lissencephaly in the parietal and occipital lobes. Camera lucida rendering to the right shows a region of disruption (grey) demonstrating a disruption in the lamination of the cortex. F. Cobblestone lissencephaly (Type II lissencephaly). Axial T2-weighted brain MRI of type II or cobblestone lissencephaly. Note the cobblestone appearance of the thinned cortex, absent corpus callosum, and severely enlarged ventricles. Camera lucida rendering to the right shows regions of disruption (grey) demonstrating nodules of neurons on the surface of the cortex. 
Table 1

Malformations of cortical development with associated genes and clinical features

\begin{tabular}{|c|c|c|c|}
\hline Developmental stage & Cortical malformation & Genetic cause & Clinical features \\
\hline \multicolumn{4}{|l|}{ Abnormal neurogenesis } \\
\hline & \multirow[t]{4}{*}{ Microcephaly } & $A S P M$ & \multirow{4}{*}{$\begin{array}{l}\text { Mental retardation, not generally associated with epilepsy, } \\
\text { autosomal recessive inheritance }\end{array}$} \\
\hline & & Microcephalin & \\
\hline & & $C D K 5 R A P 2$ & \\
\hline & & $C E N P J$ & \\
\hline & Hemimegalencephaly & Unknown & $\begin{array}{l}\text { Mental retardation, early onset seizures (frequently intractable } \\
\text { epilepsy), +/- neurocutaneous syndrome }\end{array}$ \\
\hline & Focal cortical dysplasia & Unknown & Most common, focal and generalized Seizures \\
\hline \multicolumn{4}{|c|}{ Abnormal neuronal migration } \\
\hline & \multirow[t]{2}{*}{ Periventricular heterotopia } & $F L N A$ & $\begin{array}{l}\text { Normal intelligence, adolescent onset seizures, } X \text {-linked disorder } \\
\text { with male lethality }\end{array}$ \\
\hline & & $A R F G E F 2$ & $\begin{array}{l}\text { Mental retardation, microcephaly, autosomal recessive inheritance, } \\
\text { rare }\end{array}$ \\
\hline & Subcortical band heterotopia & $D C X$ & $\begin{array}{l}\text { Subcortical band heterotopia in females, mental retardation, } \\
\text { epilepsy, X-linked disorder }\end{array}$ \\
\hline & \multirow[t]{5}{*}{ Lissencephaly } & LIS1 & $\begin{array}{l}\text { Miller-Dieker syndrome (characteristic facial features), autosomal } \\
\text { dominant inheritance }\end{array}$ \\
\hline & & $D C X$ & Lissencephaly in males, $\mathrm{X}$-linked \\
\hline & & $T U B A 1 A$ & $\begin{array}{l}\text { Lissencephaly, clinical features similar those caused by } L I S 1 \text { and } \\
D C X \text {, de novo mutations }\end{array}$ \\
\hline & & $A R X$ & $\begin{array}{l}\text { Associated with ambiguous genitalia, hypothalamic dysfunction, } \\
\text { neonatal epilepsy, X-linked disorder }\end{array}$ \\
\hline & & $R E L N$ & $\begin{array}{l}\text { Associated with cerebellar hypoplasia, epilepsy, autosomal recessive } \\
\text { inheritance }\end{array}$ \\
\hline \multicolumn{4}{|c|}{ Abnormal arrest in neuronal migration } \\
\hline & \multirow[t]{3}{*}{ Cobblestone lissencephaly } & Fukutin & Fukuyama congenital muscular dystrophy \\
\hline & & POMGnT1 & Muscle-eye-brain disease \\
\hline & & POMT1 & Walker-Warburg Syndrome \\
\hline \multicolumn{4}{|c|}{ Abnormal neuronal organization } \\
\hline & Polymicrogyria & GPR56 & Bilateral frontoparietal polymicrogyria, Epilepsy \\
\hline & Schizencephaly & $E M X 2$ & Type 2 (open cleft) \\
\hline
\end{tabular}

